\title{
Profile of Biofilm-Producing Staphylococcus epidermidis from Intravenous Catheter Colonisation at Prof. Dr. Margono Soekarjo Hospital Purwokerto
}

\author{
Dwi Utami Anjarwati ${ }^{*}$ ), Wahyu Siswandari² ${ }^{\text {and IDSAP Peramiarti }}{ }^{1}$
}

1. Dept of Microbiology, Medical Faculty of Jenderal Soedirman University, Dr Gumbreg Nomor I, Medical Street, Mersi, Purwokerto, 53112

2. Dept of Pathology Clinic, Medical Faculty of Jenderal Soedirman University-Margono Soekarjo Hospital, Dr Gumbreg Nomor I, Medical Street, Mersi, Purwokerto, 53112

\section{Info Article}

Submitted: $3-7-2018$

Revised: 9-8-2018

Accepted: 13-2-2019

*Corresponding author Dwi Utami Anjarwati

Email:

dwi.anjarwati@unsoed.ac.id

\section{ABSTRACT}

Staphylococcus epidermidis developed to be a significant human pathogen due to the ability to produce biofilm. The most significant infections of S.epidermidis found in the use of medical devices such as an intravenous catheter. Furthermore, the biofilm is more resistant to antibiotics up to 1000 times more than free-bacteria. This simple survey aimed to describe the profile of biofilm-producing S. epidermidis from intravenous catheter colonisation of some patients in surgical and internal medicine wards at the Margono Soekarjo hospital, Purwokerto, and the antibiotics resistance pattern. A vitek® 2 compact (Enseval Medika Prima) was performed to identify the bacterial species and to examine 73 antibiotics for understanding the resistance pattern automatically. The optical density (OD) representing the ability of S. epidermidis to produce biofilms was measured by Microtiter plate biofilm assay with crystal violet staining. A scanning electron microscopy was done to compare the thickness of the ultrastructure of biofilm-producing S. epidermidis visually. The present study found that 2 of 8 Gram-positive bacteria (25\%) were biofilm-producing $S$. epidermidis. One of $S$. epidermidis was moderate whereas the other was high biofilm-producing bacteria. Images of SEM showed that a high biofilm-producing $S$. epidermidis has a thicker ultrastructure of biofilm than the moderate biofilm-producing, whereas a control, the weak biofilm-producing S. epidermidis ATCC 12228 has the least biofilm. Both of $S$. epidermidis strains were sensitive to Gentamicin, Moxifloxacin, Quinupristin/Dalfopristin, Linezolid, Vancomycin, Doxycycline, Minocycline, Tetracycline, Tigecycline, and Nitrofurantoin. Furthermore, both S. epidermidis strains were resistant to the other (63) antibiotics. In conclusion, two strains of $S$. epidermidis in this study have different capabilities to form the biofilm which showed that high biofilmproducing strain was thicker than moderate biofilm-producing strain by scanning electron microscopy. However, both of them were resistant to the same number of antibiotics.

Key words: Biofilm, intravenous catheter, colonisation, S. epidermidis

\section{INTRODUCTION}

Medical devices-associated infection potentially cause some severe clinical problems. In general, phagocyte activity and polymorphonuclear leukocytes decrease in the use of invasive medical devices. For that reason, when microorganisms have a chance to reach medical devices surface, they will be attached, and biofilm formation can arise (Gottenbos et al., 2002). The use of invasive medical devices such as intravenous catheters is a risk factor for Staphylococcus sp. particularly Staphylococcus epidermidis in growing up in a biofilm stage (Fitzpatrick et al., 2005). 


\section{MATERIAL AND METHODS}

\section{Bacterial species and antibiotics susceptibility}

The bacterial strains were isolated from 39 proximal tips of the intravenous catheters from the patients in surgical and internal medicine wards of Prof. Dr Margono Soekarjo hospital, Purwokerto, on July-August, 2014. Isolates were taken from the piece of the intravenous catheter proximal tips at the catheter removal process aseptically. The proximal catheter tip is the site of catheter insertion in the blood vessels of a patient who can act as a port d'entry of infections (O'Grady et al., 2011). Isolates were not taken from other parts of the intravenous catheter such as the urine bag because they were directly related to the vein and were sterile.

A vortex and viable count method were performed to measure intraluminal and extraluminal biofilm (Donlan and Costerton, 2002). Briefly, about $3 \mathrm{~cm}$ of the proximal tip of the intravenous catheter in the sterile aquadest was vortexed for $2 \mathrm{~min}$. The isolates were cultured on the blood agar (OXOID) plate at $37^{\circ} \mathrm{C}$ for $24 \mathrm{~h}$ (overnight culture). A vitek ${ }^{\circledR} 2$ compact (Enseval Medika Prima) was performed to identify the bacterial species and to examine the antibiotics resistance. Antimicrobial Susceptibility Testing (AST) done by a vitek ${ }^{\circledR} 2$ compact (Enseval Medika Prima) be able to used to predict how pathogens will respond to particular antimicrobials automatically (Blondel-Hill et al., 2006). Therefore, data obtained by using this tool are data about bacterial species and data of antibiotics sensitivity along with its MIC value.

As many as 73 antibiotics tested include Cefoxitin, Flomoxef, Latamoxef, Benzylpenicillin, Nafcillin, Amoxicillin, Ampicillin, Carbenicillin, Ticarcillin, Azlocillin, Mezlocillin, Piperacillin, Piperacillin/Tazobactam, Cloxacillin, Dicloxa-cillin, Flucloxacillin, Methicillin, Oxacillin, Cefaclor, Cefadroxil, Cefalexin, Cefalotin, Cefazolin, Cefetamet, Cefonicid, Cefprozil, Cefradine, Cephapirin, Loracarbef, Cefamandole, Cefpodo-xime, Ceftibuten, Cefmenoxime, Cefoperazone, Cefotaxime, Ceftazidime, Ceftizoxime, Ceftriaxone, Cefepime, Cefpirome, Doripenem, Ertapenem, Faropenem, Imipenem, Meropenem, Gentamicin High Level, Streptomycin High Level, Gentamicin, Ciprofloxacin, Levofloxacin, Moxifloxacin, Inducible Clindamycin Resistance, Azithromycin, Clarithromycin, Erythromycin, Clindamycin, Quinupristin /Dalfopristin, Linezolid, Vancomycin, Doxycycline, Cefuroxime, Cefmetazole, Cefotetan, Cefoxitin, Cefdinir, Cefditoren, Cefixime, Mino- cycline, Tetracycline, Tigecycline, Nitrofurantoin, Rifampicin, Trimethoprim / Sulfamethoxazole. The isolates stored in Tryptic Soy Broth (TSB, OXOID) and $15 \%$ glycerol in $-80^{\circ} \mathrm{C}$.

\section{Biofilm assay}

Biofilm optical density (OD) was measured by using microtiter plate biofilm assay with crystal violet staining, as done previously with some modification (Anjarwati et al., 2017; Merritt et al., 2011). The values of OD describe an index of biofilms formation. Briefly, after a dilution (1:100) in fresh Tryptic Soy Broth, the bacteria from the overnight cultures in Tryptic Soy Broth and the $20 \mu \mathrm{L}$ of cultures were inoculated into fresh Tryptic Soy Broth $(200 \mu \mathrm{L})$ in each well. After $24 \mathrm{~h}$ of incubation at $37^{\circ} \mathrm{C}$, each well was washed off three times by using phosphate buffer saline (PBS), OXOID, pH 7.3 to remove planktonic bacteria. Then the adherent bacteria stained with $100 \mu \mathrm{L} 1 \%$ crystal violet. After which, 5\% acid Isopropanol $(5 \% \mathrm{v} / \mathrm{v} 1 \mathrm{M} \mathrm{HCl}$ in 2-propanol) added in each well. The absorbance at an appropriate range wavelength $(630 \mathrm{~nm})$ was determined to measure the stained biofilms quantitatively by using a microplate reader (ELX800, Bio-Tek instruments).

\section{Scanning electron microscopy}

Scanning electron microscopy was implemented to compare the thickness of biofilmproducing $S$. epidermidis strains ultrastructure visually. Briefly, S.epidermidis ATCC35984 from the overnight cultures in TSB then diluted in TSB (1:100). Moreover, as much as $50 \mu \mathrm{L}$ cultures inoculated into $13 \mathrm{~mm}$ sterile coverslips (Thermo Scientific Nunc), which laid on the bottom of 6 wells plate with TSB $(5 \mathrm{~mL})$ in each well. Each well was washed three times with PBS to eliminate free-cells following $24 \mathrm{~h}$ incubation $\left(37^{\circ} \mathrm{C}\right)$. Furthermore, the cover glass was immersed in $70 \%$ methanol for $20 \mathrm{~min}$ at room temperature for fixation; then, it was dried overnight at room temperature. Finally, the dry cover glasses were coated twice with platinum vanadium by using sputter ion. Before observed by using SEM, the cover glasses attached to the double-side tape carbon (Anjarwati et al., 2017; Setiawan et al., 2012)

\section{Data analysis}

Profile of biofilm-producing S. epidermidis in this study was analysed descriptively using the univariate method. The interpretation of the 
biofilm production has used a formulation of optical density cut-off value $(O D c)=$ average OD of negative control $+3 \times$ SD of the negative control. The criteria: Non/weak $\leq$ ODc / ODc $<\sim \leq 2 \mathrm{x}$ ODc ; Moderate 2x ODc $<\sim \leq 4 \mathrm{x}$ ODc ; high $>4 \mathrm{x}$ ODc (Hassan et al., 2011). Meanwhile, the MIC value of each antibiotic tested was obtained automatically from the vitek ${ }^{\circledR} 2$ compact results.

\section{Ethics}

This study approved by the health research ethics committee of the medical faculty of Diponegoro University and Kariadi hospital, Semarang.

\section{RESULTS AND DISCUSSION}

In the present study, the isolates were taken from 39 proximal tips of the intravenous catheter of patients in the surgery and internal medicine wards of Prof. Dr Margono Soekarjo hospital, Purwokerto. After vortex and viable count method, species identification done by a vitek ${ }^{\circledR} 2$ compact as well an antibiotic sensitivity test. To determine biofilms optical density (OD), a microtiter plate biofilm assay by using staining of crystal violet was performed. Then, the thickness of biofilm ultrastructure compared by using SEM visually.

$S$. epidermidis found was 2 of 8 Grampositive bacteria (25\%). The type of all bacteria has published as a poster in a previous $9^{\text {th }}$ National Symposium of IARW and annual scientific meeting of Indonesian Society for Clinical Microbiology. The other bacteria were $S$. haemolyticus (1), S. hominis (2), E.faecium (1), $K$. rosea (1), L mesenterdfghgdfhoides (1) (Anjarwati et al., 2014). This paper present mainly the potency of $S$. epidermidis to produce biofilm. Both S. epidermidis were biofilm-producing bacteria, one of them was moderate $(\mathrm{Se} 2)$ whereas the other was a high (Se1) biofilm-producing bacteria. The ODc value in this study was 0.12 . A moderate biofilm-producing bacteria has the optical density range of $0.2422<. . . \leq 0.4844$. Meanwhile, a high biofilm-producing bacteria has an optical density of more than 0.4844 . This study found differences in optical density between Se1 and Se2 biofilms (Figure 1).

Furthermore, SEM showed the different thickness of the biofilm ultrastructure (Figure 2). High biofilm-producing $S$. epidermidis consist of more layers biofilm than moderate biofilm. Meanwhile, the control bacteria, S. epidermidis
ATCC 12228, a weak biofilm-producing bacteria showed only a small number of biofilm.

In this simple survey by using vitek ${ }^{\circledR} 2$ compact automatically reported that both $S$. epidermidis (100\%) sensitive to Gentamicin, Moxifloxacin, Quinupristin / Dalfopristin, Linezolid, Vancomycin, Doxycycline, Minocycline, Tetracycline, Tigecycline, and Nitrofurantoin (Figure 3). Whereas both of S. epidermidis (100\%) was resistance to the other $86.3 \%$ (63 of 73) antibiotics.

This study presents the profile of biofilmproducing S. epidermidis (Figures 1 dan 2). The results indicated that in this study biofilmproducing $S$. epidermidis were found as colonisation on the intravenous catheter. Colonisation is a critical point of medical devices associated with infection. Additionally, the fragile steadiness of colonisation and infection is frequently sustained for months (Fux et al., 2009). As a biofilm-producing bacteria, S. epidermidis then can adhere to a surface in the initiation phase, followed by formation of microcolonies, which grow into a mature biofilm structure to disperse phase (Agarwal et al., 2010).

There are no standardised procedures thus far used regularly to define the antibiotic sensitivity of biofilms-producing bacteria (Estela and Alejandro, 2012). In some cases, antibiograms showed susceptibility against some microorganisms from medical devices, but that medical devices associated infection fail to be eliminated by the same antibiotics (Fux et al., 2005). In this study, the antibiotic sensitivity test done by a vitek® 2 Compact. The sensitivity test and identification of species carried out automatically at the same time. The advantages of this tool are practical and useful in detecting species. However, sensitivity test data obtained for species that are not pathogenic was incomplete, such as data of MIC. Both $S$. epidermidis strains, either it produces a moderate or a high biofilm, are resistant to the same antibiotics.

This study revealed that two strain of S. epidermidis $(100 \%)$ sensitive to Gentamicin (aminoglycoside), Moxifloxacin (quinolone), Quinupristin/ Dalfopristin (streptogramin), Linezolid (oxazolidinone), Vancomycin (glycopeptide), Tigecycline (glycylcycline), Nitrofurantoin and three kinds of tetracycline (Doxycycline, Minocycline, Tetracycline), but resistant to other 63 of $73(86.3 \%)$ antibiotics. 


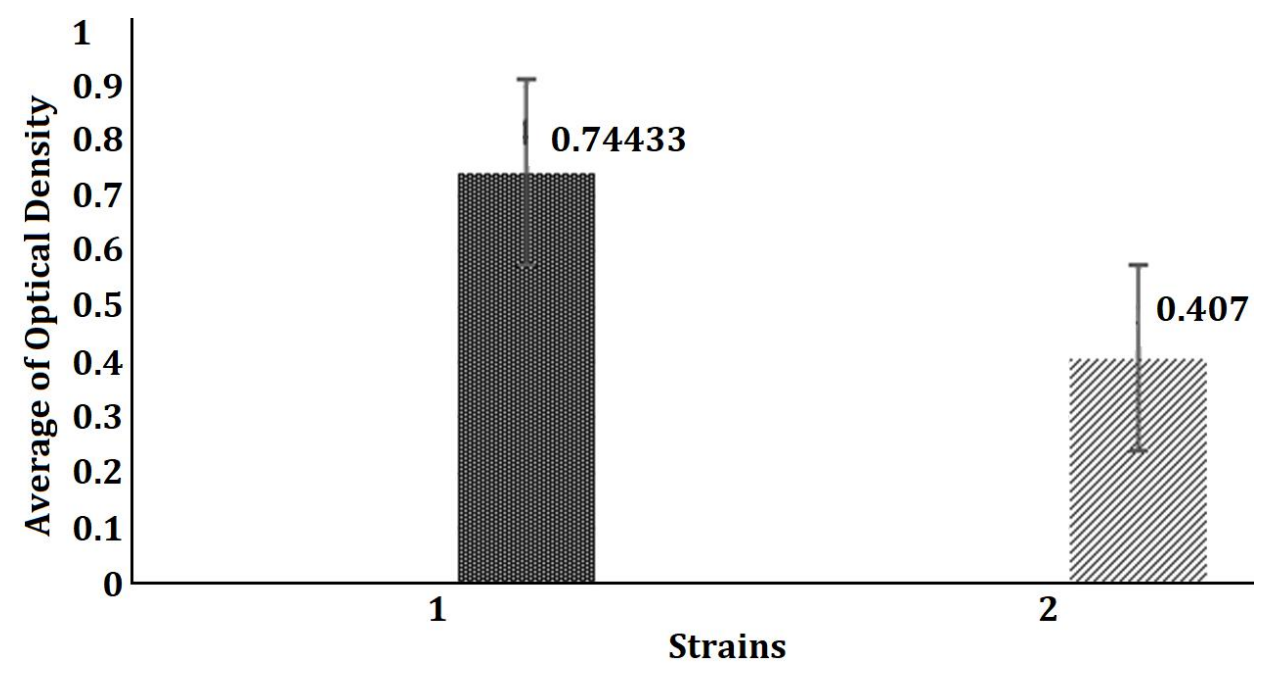

Figure 1. Biofilm-producing S. epidermidis (1= strain 1 of $S$. epidermidis (Se1), High biofilm-producing S. epidermidis, 2 = Strain 2 of $S$. epidermidis (Se2), moderate biofilm-producing $S$. epidermidis ) $\mathrm{ODc}=$ 0,12 (Moderat : $0.2422<\ldots . \leq 0.4844$; High : > 0.4844).

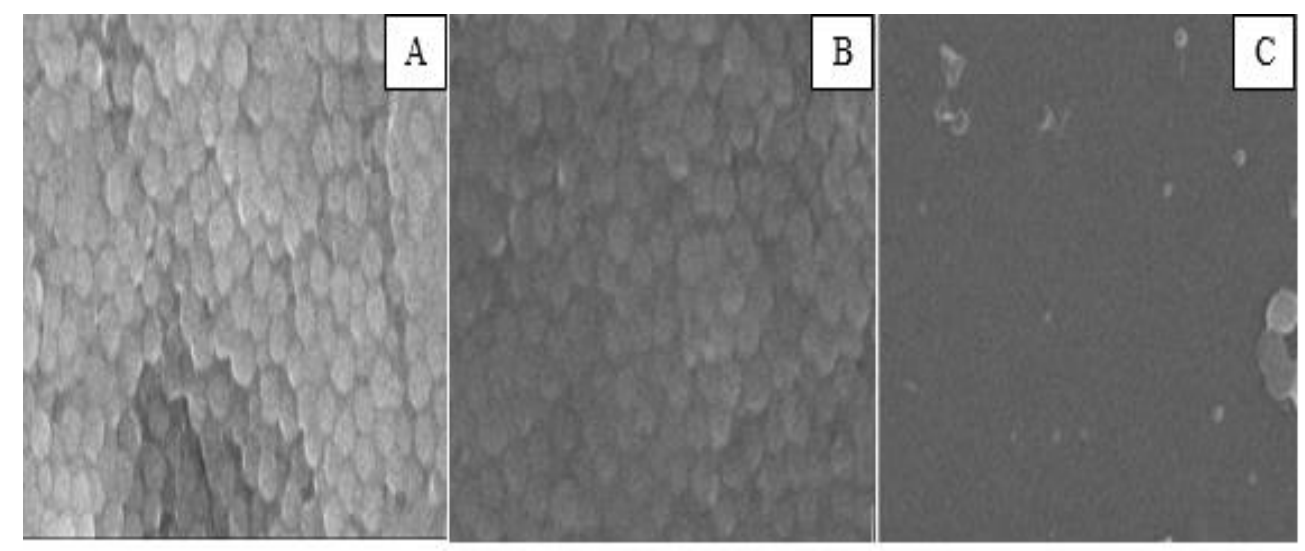

Figure 2. Images of SEM. A. High biofilm-producing S. epidermidis (Se1); B. Moderate biofilm-producing $S$. epidermidis (Se2); C. Weak biofilm-producing S. epidermidis ATCC 12228. Magnification: 20.000 X.

The antibiotics resistance mechanisms of biofilms and planktonic bacteria are different. The antibiotics resistance mechanisms in planktonic bacteria consist of efflux pumps, modifying enzymes, target mutations outer membrane impermeability (Estela and Alejandro, 2012; Poole, 2002). Meanwhile, biofilm-producing bacteria has been presented to have their intrinsic mechanisms of resistance. Multi mechanisms suggested to account for antibiotic resistance of biofilm bacteria such as the low or incomplete penetration of the antibiotics into biofilm, a chemical micro environment alteration within the biofilm, counter balancing enzymatic, functional hetero-geneity, slow growth and persistent cells and the modification of biofilm phenotype due to adaptive mechanisms to stress (such as efflux pumps and alterations in the membrane). Consequently, these mechanisms should be measured to explain therapeutic failure in the management of patients for whom laboratory outcomes show proper sensitivity patterns (Estela and Alejandro, 2012).

Data of infections caused by biofilmproducing bacteria particularly in the use of invasive medical devices have not been found widely in Indonesia. Studies and publications associated with these infections nationally 
Table I. Proper sensitive antibiotics to both biofilm-producing S. epidermidis strain

\begin{tabular}{ccc}
\hline Antibiotics & Sensitivity & MIC \\
\cline { 3 - 3 } & & S. epiermidis \\
\hline Gentamicin & $\mathrm{S}$ & $\leq 0.5$ \\
Moxifloxacin & $\mathrm{S}$ & 2 \\
Quinupristin/Dalfopristin & $\mathrm{S}$ & $\leq 0,25$ \\
Linezolid & $\mathrm{S}$ & 1 \\
Vancomycin & $\mathrm{S}$ & 1 \\
Doxycyclin & $\mathrm{S}$ & - \\
Minocycline & $\mathrm{S}$ & - \\
Tetracycline & $\mathrm{S}$ & 2 \\
Tigecycline & $\mathrm{S}$ & $\leq 0.12$ \\
Nitrofurantoin & $\mathrm{S}$ & $\leq 16$ \\
\hline
\end{tabular}

S = sensitive; The table performs 10/73 (13.7\%) antibiotics which have proper sensitivity to both of biofilm-producing S. epidermidis. Meanwhile, both strains were 100\% (2/2) resistant to others (63 antibiotics) ; MIC value obtained automatically from vitek ${ }^{\circledR} 2$ compact.

need to be improved. The difference between the resistance mechanisms of planktonic bacteria and biofilm bacteria is an interesting point for researchers to investigate this phenomenon.

\section{CONCLUSION}

Two clinical strains of $S$. epidermidis from the patients in surgical and internal medicine wards at Prof. Dr Margono Soekarjo hospital, Purwokerto have different capabilities to form the biofilm which showed that high biofilm-producing strain was thicker than moderate biofilmproducing strain by scanning electron microscopy. However, both of them were resistant to the same number of antibiotics.

\section{ACKNOWLEDGEMENTS}

Thanks to Ministry of the Higher Education Republic of Indonesia and Jenderal Soedirman University, Purwokerto for the grant, Enseval Medika Prima and Medical Faculty of Diponegoro University for Facilities.

\section{REFERENCES}

Agarwal A., Singh KP., and Jain A. 2010. Medical significance and management of staphylococcal biofilm. FEMS Immunology \& Medical Microbiology, 58(2), 147-160. https://doi.org/10.1111/j.1574695X.2009.00601.x

Anjarwati DU., Nuryastuti T., Riwanto I., and Wahyono H. 2017. Effects of Chloroprocta sp. maggot filtrates on extracellular matrix reduction and embedded Staphylococcus epidermidis viability. Malaysian Journal of Microbiology, 13(3).

Anjarwati DU., Siswandari W., and Peramiarti I. 2014. Antibiotic Resistance of BiofilmProducing Gram Positive Bacteria of Intravena Catheter in Margono Soekarjo Hospital Purwokerto. In 9th National Symposium of IARW and annual scientific meeting of Indonesian Society for Clinical Microbiology, "Antimicrobial policies and practices for patient safety. Jakarta.

Blondel-Hill E., Jang W., Lee I., Borton N., Book L., and Thomas E. 2006. Comparison of Phoenix ${ }^{T M}$ and Vitek ${ }^{\circledR} 2$ Compact, For Performance of Identification and Susceptibility Testing, Workflow, and Time to Report (5 No. 3). San Francisco. Retrieved from https://www.biomerieux-usa.com

Donlan RM., and Costerton JW. 2002. Biofilms: survival mechanisms of clinically relevant microorganisms. Clinical Microbiology Reviews, 15(2), 167-193. https://doi.org/10.1128/CMR.15.2.167193.2002

Estela CRL., and Alejandro PR. 2012. Biofilms: A Survival and Resistance Mechanism of Microorganisms. In M. Pana (Ed.), Antibiotic Resistant Bacteria. Rijeka: IntechOpen. https://doi.org/10.5772/28504

Fitzpatrick F., Humphreys H., and O'Gara JP. 2005. The genetics of staphylococcal biofilm formation\&\#x2014; will a greater understanding of pathogenesis lead to 
better management of device-related infection? Clinical Microbiology and Infection, 11(12), 967-973. https://doi.org/10.1111/j.14690691.2005.01274.x

Fux CA., Costerton JW., Stewart PS., and Stoodley P. 2005. Survival strategies of infectious biofilms. Trends in Microbiology, 13(1), 3440.

Fux CA., Stoodley P., Shirtliff M., and Costerton JW. 2009. The Functional Resistance of Bacterial Biofilms. In D. L. Mayers (Ed.), Antimicrobial Drug Resistance: Mechanisms of Drug Resistance (pp. 121-131). Totowa, NJ: Humana Press. https://doi.org/10.1007/978-1-59745180-2_11

Gottenbos B., Busscher HJ., van der Mei HC., and Nieuwenhuis P. 2002. Pathogenesis and prevention of biomaterial centered infections. Journal of Materials Science: Materials in Medicine, 13(8), 717-722. https://doi.org/10.1023/A:101617550275 6

Hassan A., Usman J., Kaleem F., Omair M., Khalid A., and Iqbal M. 2011. Evaluation of different detection methods of biofilm formation in the clinical isolates. Brazilian Journal of Infectious Diseases, 15, 305-311. Retrieved from

http://www.scielo.br/scielo.php?script=sci _arttext\&pid=S1413$86702011000400002 \& n r m=i s o$

Merritt JH., Kadouri DE., and O'Toole GA. 2011. Growing and Analyzing Static Biofilms. Current Protocols in Microbiology, 22(1), 1B.1.1-1B.1.18.

https://doi.org/10.1002/9780471729259. mc01b01s22

O'Grady NP., Alexander M., Burns LA., Dellinger EP., Garland J., Heard SO., (HICPAC) H. I. C. P. A. C. 2011. Guidelines for the prevention of intravascular catheter-related infections. Clinical Infectious Diseases: An Official Publication of the Infectious Diseases Society of America, 52(9), e162-e193. https://doi.org/10.1093/cid/cir257

Poole K. 2002. Mechanisms of bacterial biocide and antibiotic resistance. Journal of Applied Microbiology, 92(s1), 55S-64S. https://doi.org/10.1046/j.13652672.92.5s1.8.x

Setiawan VM., Estoepangestie S., and Koesdarto S. 2012. Pembentukan Biofilm oleh Streptococcus uberis Terkait dengan Infeksi Kronis Intramammary. Jurnal Biosains Pascasarjana, 14(3), 153-157. 